\title{
ORIGINE DU VIEUX SLAVE
}

Si nous consultons le Stownik starożytności stowiańskich, nous trouverons s. v. Panońskie narzecza l'article de Lehr-Splawiński, où nous apprendrons que

na terenie Panonii rozwijali około 860 r. ożywioną działalność misyjną bracia soluńscy Konstantyn i Metody... i że đziałalność ta była popierana życzliwie przez ówczesnego władcę Panonii, Kocelja. $Z$ faktem tym wiązano dawniej teorię o panońskim pochodzeniu głównych zabytków scs. i w Panonii doszukiwano się źr. pochodzenia ich języka, dając mu na tym tle nazwę "starosłoweńskiego" (Kopitar, Miklosich) w przypuszczeniu, że podówczas mówiono w Panonii narzeczem należącym do zakresu języka dzis. Słoweńców. Ta „panońska” teoria pochodzenia języka scs. została... obalona.

L'article est suivi d'une brève bibliographie où figure, en premier lieu, le livre de Jagić Entstehungsgeschichte der kirchenslavischen Sprache.

En outre dans la grammaire du vieux slave de Lehr-Spławiński ${ }^{1}$, nous trouverons un renseignement selon lequel ,język staro-cerkiewno-słowiański pochodzeniem swoim należał... do narzeczy południowosłowiańskich, ściślej: bułgarsko-macedońskich, czego w zgodzie ze wskazówkami historycznymi dowodzą takie właściwości jego budowy, jak przede wszystkim rozwój prasłow. połączeń * $t,{ }^{*} d>\check{s} t, \check{z} d \ldots, .$, bliskość wymowy ě i ja... itp."

Pareillement, on apprendra, dans la grammaire de Feuillet ${ }^{2}$, que "le principal argument pour étayer l'équation vieux slave = vieux bulgare est le traitement spécifique de slave commun * $t j$ et *dj qui donnent $\breve{s t}, z \check{z} d$ en bulgare, comme dans la langue de Cyrille et Méthode".

Comme, pour prouver l'identité du vieux slave et du vieux bulgare, on invoque uniquement des critères phonétiques, rappelons que l'orientaliste allemand du XVIIe siècle Ludolf affirmait déjà que "die Sprachverwandtschaft offenbart sich nicht im Wörterbuch, sondern in der Grammatik"3. Pendant les 300 dernières années, tellement d'autorités ont approuvé l'opinion de Ludolf qu'elle est devenue un dogme de la linguistique. Pourtant il nous est venu à l'esprit de le confronter avec des faits et ainsi nous sommes arrivé à la conclusion qu'en réalité, c'est le vocabu-

${ }^{1}$ T. Lehr-Sptawiński et Cz. Bartula, Zarys gramatyki jezyka staro-cerkiewno-stowiańskiego na tle porównawczym, 4 e éd., Wroctaw, 1959, p. 4.

2 J. Feuillet, Grammaire historique du bulgare, Paris, 1999, p. 11.

${ }^{3}$ H. Schuchardt, Hugo Schuchardt-Brevier. Ein Vademecum der allgemeinen Sprachwissenschaft, $2 e$ éd., Halle (Saale), 1928, p. 198. 
laire (et non la phonétique et la flexion) qui décide du degré de la parenté des langues ${ }^{4}$. Voici des arguments à l'appui de cette thèse.

Non seulement les slavistes, mais même les profanes ayant une connaissance rudimentaire du polonais, de l'ukrainien et du russe savent que le polonais est plus apparenté à l'ukrainien qu'au russe. Pourtant, si l'on prenait en considération la phonétique, on constaterait qu'il y a plus de ressemblances entre le polonais et le russe qu'entre le polonais et l'ukrainien. Entre le polonais et le russe, on peut signaler les convergences phonétiques suivantes: $1^{\circ}$ en ukrainien $g>h$, alors qu'en polonais et en russe le $g$ se maintient; $2^{\circ}$ en ukrainien $\check{e}>i$, tandis qu'en russe dans tous les cas et en polonais dans la plupart des cas $\breve{e}>e ; 3^{\circ}$ en ukrainien $e$ et $o$ aboutissent, dans une syllabe fermée, à $i$, alors qu'en polonais et en russe ces voyelles conservent, dans beaucoup de cas, leur timbre primitif; $4^{\circ}$ en polonais et en russe les consonnes se palatalisent devant les voyelles antérieures, ce qui n'est pas le cas en ukrainien; $5^{\circ}$ en ukrainien $i>y$, alors qu'en polonais et en russe le $i$ reste tel quel; $6^{\circ}$ en fin de syllabe, le $v$ subit en ukrainien une vocalisation, tandis qu'en polonais et en russe le $v$ conserve son caractère consonantique; $7^{\circ}$ la consonne se trouvant devant bj devient en ukrainien une géminée, alors qu'elle se maintient comme simple en polonais et en russe; $8^{\circ}$ 1'affriquée résultant des $2 \mathrm{e}$ et $3 \mathrm{e}$ palatalisations conserve en ukrainien la mouillure, tandis qu'en polonais et en russe elle subit une dépalatalisation, cf. ukr. vulycja en regard de pol. et russe ulica; $9^{\circ}$ en ukrainien les consonnes sonores finales restent telles quelles, alors qu'en polonais et en russe elles s'assourdissent; $10^{\circ}$ des consonnes prothétiques apparaissent plus souvent en ukrainien qu'en polonais et en russe, cf. ukr. vin en face de pol. et russe on. A ces 10 convergences les plus frappantes entre le polonais et le russe, nous ne saurions opposer que 2 ressemblances phonétiques entre le polonais et l'ukrainien: $1^{\circ}$ absence de l'akanie; $2^{\circ}$ le fait qu'après $c$ le $i$ se maintient en russe, tandis qu'en polonais et en ukrainien il aboutit à $y$. Somme toute, en examinant les traits phonétiques, on arrive à la conclusion qu'il y a plus de ressemblances entre le polonais et le russe qu'entre le polonais et l'ukrainien. Mais il suffit d'appliquer notre méthode de comparaison du vocabulaire dans des textes parallèles ${ }^{5}$ pour obtenir un autre résultat.

Dans le manuel de Kondrašov, il y a un fragment d'un roman russe traduit en d'autres langues slaves. La comparaison de ce fragment (les mots présentant la même racine sont considérés comme apparentés) en russe, ukrainien et polonais a révélé qu'il existait 13 concordances lexicales polono-ukrainiennes (bezstronny, bezstoronnij, bezpristrastnyj; czy, čy, li; dobrze, dobre, chorošo; hartować się, hartuvatysja, zakaljat'sja; jak (2 fois), jak, kak; kropla, kraplyna, kaplja; od, vid, s; ostatni, ostannij, poslednij; rok (2 fois), rik, god; zamyślić się, zamyslytysja, zadumat'sja; $z, z$,

\footnotetext{
4 W. Mańczak, De la préhistoire des peuples indo-européens, Kraków, 1992, p. 22 suiv.

5 W. Mańczak, Nouvelle méthode de recherches linguistiques et ethnogénétiques: comparaison du vocabulaire dans des textes parallèles, Annali del Dipartimento di Studi del Mondo Classico e del Mediterraneo Antico. Sezione linguistica, 12, 1990, p. 243-256.
} 
$p o$ ) et 1 concordance lexicale polono-russe (nemalo, nemalo, čymalo). On voit donc que la comparaison du vocabulaire dans des textes parallèles conduit à la conclusion juste que le polonais est plus apparenté à l'ukrainien qu'au russe.

Autre exemple. D'après une opinion unanime, le latin est plus apparenté au français qu'au gotique, le gotique est plus apparenté à l'anglais qu'au vieux slave et le polonais est plus apparenté au bulgare qu'au lituanien. Nous avons quand même examiné des textes parallèles dans ces langues et avons établi que les convergences flexionnelles et lexicales dans ces langues se présentaient de la façon suivante:

$\begin{array}{lcc} & \text { Ressemblances flexionnelles } & \text { Ressemblances lexicales } \\ \text { Latin et gotique } & 103 & 47 \\ \text { Latin et français } & 18 & 222 \\ \text { Gotique et vieux slave } & 83 & 74 \\ \text { Gotique et anglais } & 31 & 93 \\ \text { Polonais et lituanien } & 62 & 51 \\ \text { Polonais et bulgare } & 52 & 291\end{array}$

Il résulte de ces données que l'opinion juste selon laquelle le latin est plus apparenté au français qu'au gotique, que le gotique est plus apparenté à l'anglais qu'au v. slave et que le polonais est plus apparenté au bulgare qu'au lituanien s'appuie sur des concordances lexicales, et non flexionnelles. Il n'est pas difficile d'expliquer ceci. Par exemple, il suffit de tenir compte du fait qu'en polonais et en lituanien il y a sept cas et un infinitif, tandis qu'en bulgare l'infinitif n'existe pas et il y a uniquement des restes d'une déclinaison.

Ayant établi que, contrairement à l'opinion de Ludolf, c'est le vocabulaire (et non la phonétique ou la flexion) qui décide du degré de la parenté des langues, nous avons décidé d'examiner comment se présentent les concordances lexicales entre le vieux slave et les langues slaves modernes. Dans ce but, nous avons comparé huit chapitres du Codex Marianus (Matth. 2-3, Marc 8-9, Luc 14-15 et Jean 20-21) à leurs traductions en biélorusse ${ }^{6}$, bulgare ${ }^{7}$, tchèque ${ }^{8}$, bas-sorabe ${ }^{9}$, haut-sorabe ${ }^{10}$, macédonien ${ }^{11}$, polonais ${ }^{12}$, russe ${ }^{13}$, serbo-croate ${ }^{14}$, slovaque ${ }^{15}$, slovène ${ }^{16}$ et ukrainien ${ }^{17}$, à ceci près que avons tenu compte uniquement de mots indigènes.

\footnotetext{
${ }^{6}$ Novy Zapavet Hospada našaha Isusa Chrysta, London, 1948.

${ }^{7}$ Biblija ili Sveštenoto Pisanie na Starija i Novija Zavětb, Sofija, 1924.

${ }^{8}$ Bibli Svatá aneb všecka svatá pisma Starého i Nového Zákona, Praha, 1949.

${ }^{9}$ Nowy Testament naschogo Knèsa Jesom Kristußa do ßerskoje rèzy pschestawjony, Barlin, 1860.

${ }^{10}$ Swjate Pismo Noweho Zakonja, Budyšin, 1966.

11 Le titre nous est inconnu.

12 Nowy Testament Pana naszego Jezusa Chrystusa, London [sans date].

13 Novyj Zavětb Gospoda našego Iisusa Christa, Berlinb, 1931.

14 Novi Zavjet Gospoda našega Isusa Christa, Nujork, 1950.

15 Nový Zákon Pana nášho Ježiša Krista, Trnava, 1913.

${ }^{16}$ Novi Zakon Gospoda in Zveličarja našega Jezusa Kristusa, Dunaj, 1911.

${ }^{17}$ Novyj Zapovit Hospoda j Spasytelja našoho Isusa Chrysta, London, 1949.
} 
Cette comparaison a révélé les nombres suivants de ressemblances lexicales: russe 1065 , serbo-croate 1025 , slovène 962 , macédonien 895 , bulgare 878 , polonais 856 , biélorusse 830 , ukrainien 770 , tchèque 729 , slovaque 699 , haut-sorabe 614 , bassorabe 579.

Afin de déceler certaines régularités dans ces données, il est nécessaire d'examiner chaque groupe de langues slaves à part. Commençons par les langues occidentales:

$\begin{array}{ll}\text { Polonais } & 856 \\ \text { Tchèque } & 729 \\ \text { Slovaque } & 699 \\ \text { Haut-sorabe } & 614 \\ \text { Bas-sorabe } & 579\end{array}$

Que le polonais soit en premier lieu, s'explique par le fait que l'habitat primitif des Slaves s'est trouvé dans le bassin de l'Oder et de la Vistule. Dans l'habitat primitif, la langue évolue plus lentement que dans les domaines où les langues se développent sur des substrats étrangers.

Passons aux langues orientales:

$\begin{array}{lr}\text { Russe } & 1065 \\ \text { Biélorusse } & 830 \\ \text { Ukrainien } & 770\end{array}$

Parmi toutes les langues slaves modernes, le russe ressemble le plus au vieux slave, ce qui s'explique par le fait qu'à l'époque historique le russe a subi une énorme influence de cette langue. Il suffit de mentionner que mềme sous le régime communiste on a formé de nombreux noms de villes en -grad (Leningrad, Stalingrad, Kaliningrad, etc.) et que même dans l'expression da zdravstvuet Sovetskij Sojuz tous les quatre mots proviennent du vieux slave.

Examinons enfin l'état de choses dans les langues méridionales:

$\begin{array}{lr}\text { Serbo-croate } & 1025 \\ \text { Slovène } & 962 \\ \text { Macédonien } & 895 \\ \text { Bulgare } & 878\end{array}$

On voit donc que, en ce qui concerne les convergences avec le vieux slave, le serbo-croate occupe la première place, le slovène la deuxième, tandis que le macédonien et le bulgare se trouvent en dernière place.

Voici quelques exemples pour montrer que le serbo-croate présente plus de ressemblances lexicales avec le vieux slave que le bulgare ou le macédonien: 


\begin{tabular}{|c|c|c|c|}
\hline Vieux slave & Serbo-croate & Bulgare & Macédonien \\
\hline chotěti & hotjeti & iskam & saka \\
\hline chroms & hrom & $k u c$ & sakat \\
\hline gora & gora & planina & gora \\
\hline$i z$ & $i z$ & $o t$ & od \\
\hline iziti & $i z i c ́ i$ & izlizam & izleze \\
\hline$k b$ & $k$ & pri & pri \\
\hline ljubiti & ljubiti & običam & saka \\
\hline$m b n j b j b$ & najmanji & najmalăk & pomal \\
\hline niže & niže & po-dole & pomal \\
\hline onb & on & toj & toj \\
\hline oslaběti & oslabiti & premaleja & premalee \\
\hline $\mathrm{Otb} \mathrm{Cb}$ & otac & bašta & tatko \\
\hline postydètì se & postidjeti se & sramuvam se & srami se \\
\hline posblati & poslati & izpratja & isprati \\
\hline prělomiti & prelomiti & razčupja & raskrši \\
\hline prizbvati & dozvati & povikam & povika \\
\hline prbsb & prsa & grăd & grad \\
\hline pbšenica & pšenica & žito & žito \\
\hline razuměti & razumjeti & razbiram & razbira \\
\hline r!gatisę & rugatise & prismivam se & smee se \\
\hline stbdza & staza & teka & pateka \\
\hline şžěšti & sažgati & izgorja & izgori \\
\hline ubojati sę & pobojati se & strachuvam se & uplaši se \\
\hline velbjb & velik & goljam & golem \\
\hline vyše & više & po-gore & pogore \\
\hline vbstati otb mrbtvychb & ustati iz mrtvijeh & văzkresja & voskresne \\
\hline zatvoriti & zatvoriti & zaključja & zakluči \\
\hline zъvati & zvati & kania & kani \\
\hline
\end{tabular}

Avant de présenter la cause pour laquelle le serbo-croate présente plus de ressemblances avec le vieux slave que le macédonien ou le bulgare, une digression est nécessaire. Il s'agit du fait que les vues concernant la naissance de la Slavia méridionale sont partagées. Les uns, comme Godłowski ${ }^{18}$, estiment que.les Slaves méridionaux sont arrivés de la Slavia orientale. D'autres, comme Sławski ${ }^{19}$, affirment que, à l'origine, il y a eu deux domaines séparés, le domaine macédo-bulgare et le domaine slovéno-serbo-croate, et se demandent s'il est même possible de parler d'une Slavia méridionale. Enfin, Nalepa ${ }^{20}$ croit que les Slaves méridionaux sont arrivés de la Slavia occidentale.

${ }^{18} \mathrm{~K}$. Godlowski, Pierwotne siedziby Stowian. Wybór pism pod redakcją M. Parczewskiego, Kraków, 2000.

${ }^{19}$ F. Stawski, Gramatyka języka bułgarskiego, $2 e$ éd., Warszawa, 1962, p. 3.

${ }^{20}$ J. Nalepa, Miejsce uformowania się Prastowiańszczyzny, Slavica Lundensia, 1, 1973, p. 55-114. 


\begin{tabular}{|c|c|c|c|c|c|c|c|c|c|c|c|}
\hline \multicolumn{4}{|c|}{ Slovène } & \multicolumn{4}{|c|}{ Serbo-croate } & \multicolumn{4}{|c|}{ Bulgare } \\
\hline Pol. & 364 & Russe & 331 & Pol. & 360 & Russe & 387 & Pol. & 288 & Russe & 367 \\
\hline Tchèque & 322 & B.-russe & 301 & Tchèque & 301 & B.-russe & 323 & Tchèque & 245 & B.-russe & 315 \\
\hline Slovaque & 290 & Ukr. & 261 & Slovaque & 289 & Ukr. & 296 & Slovaque & 236 & Ukr. & 283 \\
\hline & 976 & & 893 & Pol. & 950 & & 1006 & Pol. & 769 & & 965 \\
\hline
\end{tabular}

Personnellement, nous avons essayé de résoudre ce problème à l'aide de la comparaison du vocabulaire dans des textes parallèles. En tenant compte de trois langues de chaque groupe des langues slaves, nous avons établi les ressemblances lexicales suivantes que chaque langue méridionale présente avec les langues occidentales et orientales ${ }^{21}$ :

On voit donc que le slovène ressemble plus aux langues occidentales qu'aux langues orientales, tandis que l'inverse est vrai pour le serbo-croate et le bulgare. Mais faut-il en conclure que les ancêtres des Slovènes sont arrivés de la Slavia occidentale, alors que ceux des Croates, Serbes et Bulgares sont venus de la Slavia orientale? Pas nécessairement parce qu'il faut attirer l'attention sur le fait que toutes les langues occidentales présentent le plus de ressemblances lexicales avec le slovène, moins avec le serbo-croate et le moins avec le bulgare.

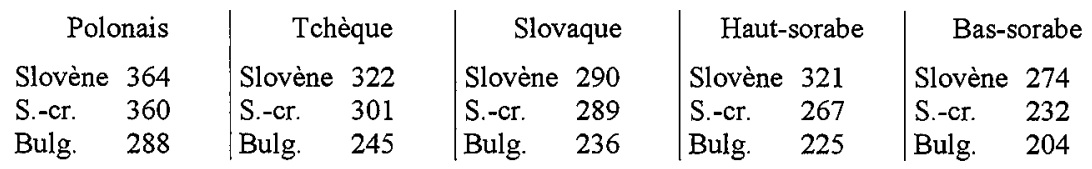

D'autre part, il est important d'insister sur ce que langues méridionales ressemblent le plus au russe, moins au biélorusse et le moins à l'ukrainien.

Le fait que les langues occidentales ressemblent le plus au slovène, moins au serbo-croate et le moins au bulgare, parle à l'appui de la thèse de Nalepa: plus un domaine est proche de la Slavia occidentale, plus la langue parlée dans ce domaine ressemble aux langues occidentales. En revanche, si les ancêtres des Slaves méridionaux étaient arrivés de la Slavia orientale, les langues méridionales auraient dû ressembler le plus à l'ukrainien, moins au biélorusse et le moins au russe. Cependant, l'inverse est vrai, ce qui s'explique par le fait qu'à l'époque historique les langues orientales, surtout le russe, ont subi une forte influence du vieux slave.

Si le vieux slave était né dans le domaine moravo-pannonien, où, selon Kopitar et Miklosich, le vieux slovène devait être employé, le vieux slave aurait dû ressembler surtout au slovène. Si le vieux slave était né dans le domaine macédo-bulgare, comme l'estiment tous les autres slavistes, il aurait dû ressembler le plus au macédonien et au

21 W. Mańczak, Przedhistoryczne migracje Stowian w świetle stownictwa, Dzieje Stowian w świetle leksyki, Kraków, 2002, p. 177-181. 
bulgare. Mais en réalité le vieux slave ressemble le plus au serbo-croate, qui est une langue intermédiaire entre le slovène d'une part et le macédonien et le bulgare de l'autre. Il en résulte, à notre avis, que le vieux slave constituait un compromis entre le parler macédo-bulgare et le dialecte moravo-pannonien. Constantin et Méthode traduisaient du grec en dialecte macédo-bulgare, qu'ils connaissaient, mais ensuite ils modifiaient partiellement leurs traductions pour qu'elles deviennent plus compréhensibles à la population qui se servait du parler moravo-pannonien.

Que, du point de vue lexical, le vieux slave ait constitué un compromis entre le dialecte macédo-bulgare et le parler moravo-pannonien, est absolument sûr. En revanche, on pourrait se demander si ce compromis ne s'appliquait pas également à la phonétique et à la flexion. Voici quelques points d'interrogation. Les slavistes considèrent comme très important le fait que $\breve{s} t$ et $\check{z} d$ existent aussi bien en bulgare qu'en vieux slave, mais il ne faut pas oublier que, jusqu'à nos jours, le macédonien littéraire présente $k^{\prime}, g^{\prime}$, et non $\check{s} t, \check{z} d$. D'autre part, il est intéressant de noter que les vieux emprunts slaves en hongrois présentent $\breve{s} t, \check{z} d$, cf. mostoha "belle-mère", rozsda "rouille". Il y a št même dans le nom de la capitale de la Hongrie. Budapest est né de la fusion de deux toponymes, Buda et Pest. Tous les deux désignent la même chose, un four pour cuire des briques, à ceci près que Buda est hongrois, tandis que Pest est slave. - Il vaut la peine de mentionner aussi que le 1 épenthétique n'existe pas en bulgare et en macédonien, mais nous le trouvons dans un vieil emprunt slave en hongrois: gereblye "râteau". - D'après le livre Die Slaven in Griechenland de Vasmer, les toponymes slaves en Grèce se caractérisent souvent par l'absence de la métathèse des liquides, qui, en vieux slave, est très rare. Peut-être les mots du type v. slave alkati ont été, à l'origine, plus nombreux, mais ils ont été éliminés sous l'influence du dialecte moravo-pannonien.

Le bulgare et le macédonien diffèrent de toutes les autres langues slaves par leur caractère très analytique, tandis que le vieux slave est synthétique. Une fois de plus, on peut se demander si, sous une forme embryonnaire, le caractère analytique du dialecte macédo-bulgare ne se manifestait pas dès le $\mathrm{IX}^{\mathrm{e}}$ siècle, mais a été éliminé sous l'influence du parler moravo-pannonien. Mais toutes ces questions sont très difficiles et nous n'avons pas l'intention d'essayer de les résoudre, d'autant plus qu'à notre avis, c'est le vocabulaire (et non la phonétique ou la flexion) qui décide du degré de la parenté des langues.

Voici la conclusion de notre article. A l'appui de leur théorie pannonienne, Kopitar et Miklosich alléguaient des traces d'une influence du vieux-haut-allemand et du latin surtout dans la plus ancienne terminologie chrétienne, c'est-à-dire dans des mots comme cerkev, oltar, post, pop, menih, papež, sreda ou maša. Les autres slavistes invoquent des critères phonétiques pour affirmer que le vieux slave est né dans le domaine macédo-bulgare. A notre avis, la vérité se trouve au milieu. La comparaison du vocabulaire indigène dans des textes parallèles nous a conduit à la conclusion que le vieux slave constituait un compromis entre le parler macédo-bulgare et le dialecte moravo-pannonien. 


\section{Povzetek \\ IZVOR STARE CERKVENE SLOVANŠČINE}

Kopitar in Miklošič sta zaradi najstarejše starocerkvenoslovanske terminologije, v kateri lahko zaznamo izposojenke tako iz stare visoke nemščine kot latinščine, trdila, da je stara cerkvena slovanščina nastala v Panoniji, kjer naj bi, po njunem mnenju, $\vee$ 9. stoletju govorili staroslovensko narečje. Danes slavisti menijo, da je stara cerkvena slovanščina nastala na makedonsko-bolgarskem področju. Za potrditev omenjene trditve navajajo fonetični dokaz: št in žd obstajata tako v makedonščini in bolgarščini kot tudi v jeziku Cirila in Metoda. Kljub temu sem se odločil, da bom primerjal avtohtono besedišče v 8. poglavju Marijanskega kodeksa (Codex Marianus) in prevode Evangelijev v sodobne slovanske jezike. Primerjava je pokazala, da se s staro cerkveno slovanščino najbolj ujema ruščina, nekoliko manj srbohrvaščina, še manj slovenščina, najmanj pa makedonščina in bolgarščina. Če bi bila panonska teorija Kopitarja in Miklošiča pravilna, bi se morala glede na besedišče s staro cerkveno slovanščino najbolj ujemati slovenščina. Če je pravilno mnenje drugih slavistov, bi se s staro cerkveno slovanščino morali najbolj ujemati makeđonščina in bolgarščina. Vendar če (ne upoštevajoč ruščine) kaže največ ujemanja v besedišču s staro cerkveno slovanščino srbohrvaščina, ki se nahaja med slovenščino na eni strani in makedonščino in bolgarščino na drugi, potem menim, da je resnica nekje vmes: stara cerkvena slovanščina tvori »kompromis « med makedonsko-bolgarskim govorom in moravsko-panonskim narečjem. Konstantin in Metod sta prevajala v makedonsko-bolgarsko narečje, vendar sta svoje prevode delno spreminjala, da bi bili razumljivi tudi ljudem, ki so govorili moravsko-panonsko narečje. 